\title{
Effects of the Perfusion Flow Rate on Skeletal Muscle Energy Metabolism and a Possible Role of Second Messengers in This Process
}

\author{
B. ŠTEFL, J. ŽURMANOVÁ
}

Department of Physiology and Developmental Biology, Faculty of Science, Charles University Prague, Czech Republic

Received January 28, 2005

Accepted March 31, 2005

On-line available April 26, 2005

\begin{abstract}
Summary
The metabolic turnover in the isolated in vitro perfused and superfused rat skeletal muscle (musculus gracilis cranialis) was enhanced by increasing the medium flow rate under relaxed conditions. In a recent study we have measured the tissue concentrations of second messengers: cyclic adenosine $3^{\prime} 5^{\prime}$ - monophosphate (cAMP), cyclic guanosine $3^{\prime} 5^{\prime}-$ monophosphate (cGMP), and D-myo-inositol 1, 4, 5-trisphosphate (IP3) under similar experimental conditions to analyze their potential role in the described stimulation of metabolic rate by changes of perfusion flow rate. The tissue levels of the two second messengers' cAMP and cGMP were not significantly changed after increasing the perfusion flow rate and they probably have no transduction role in the induced alteration of skeletal muscle metabolism. However, the IP3 content was extremely reduced after increasing flow rate. This decrease in the tissue concentration of IP3 induced by increasing the flow rate indicates the possible role of IP3 in this signal transduction, leading to changes in the cellular metabolic pathways.
\end{abstract}

Key words

Metabolism • Physiology $\bullet$ Second messengers $\bullet$ Skeletal muscle

\section{Introduction}

The regulation of energy metabolism in skeletal muscles persists in the center of interest of muscle physiologists. One of the reasons is the enormous range of the power output of muscles reflecting rates of energy utilization and bearing evidence of very powerful regulatory mechanisms of muscle cells. Skeletal muscles are considered as a chemo-mechanical converter with the main role in force generation on account of chemical energy. Besides this dominant role, which is switched on/off from the "outside" by motoric nerve, muscles of mammals possess the ability to dissipate energy without generating force. The typical example is the calorigenic effect of catecholamines or other substances (Clark et al. 1995).

Another example concerns the stimulation of metabolic rate of relaxed skeletal muscle by an increased perfusion flow rate that is also well documented (Chinet and Mejsnar 1989, Mejsnar et al. 1992). The influence of 
the perfusion flow rate on energy dissipation, oxygen consumption, and levels of selected metabolites of energy metabolism was studied in the isolated perfused and superfused rat gracilis cranialis muscle (Štefl et al. 1994, 1999, Janovská et al. 1999). Even during a low perfusion rate the delivery of oxygen was not limiting the total oxygen consumption but the muscle oxygen consumption was stimulated by increasing the perfusion flow rate. A creatine charge (e.g. the ratio of phosphocreatine to total creatine concentrations) is a suitable criterion in this muscular model for the evaluation of the energy state in muscle tissue. The low perfusion flow rate was connected with the low creatine charge and increasing the flow rate improved the creatine charge. Contrary to the general opinion that the metabolism in resting skeletal muscle is mostly oxidative, we have found a prevalence of glycolysis over oxidative phosphorylation during low perfusion flow rate of $0.054 \mathrm{ml} / \mathrm{min}$. The increase in perfusion flow rate to $0.100 \mathrm{ml} / \mathrm{min}$ changed the proportion of anaerobic to aerobic synthesis of ATP in favor of oxidative phosphorylation. Free ADP level (calculated from the supposed equilibrium of creatine kinase reaction) negatively correlated with the rate of oxygen consumption (and hence with the perfusion flow rate), which indicates that the feedback regulation of oxidative metabolism by the product of ATP hydrolysis is not responsible for the transition from glycolytic prevalence to mitochondrial prevalence of ATP synthesis after increasing the flow rate in this muscle. We concluded that increasing the perfusion flow rate is the primary pro-active stimulus leading to activation of oxidative metabolism of the resting in vitro perfused skeletal muscle (Janovská et al. 1999, Štefl et al. 1999).

Recent works studying regulation of cellular respiration have often emphasized the role of $\mathrm{Ca}^{2+}$. Three intramitochondrial citrate cycle dehydrogenases (pyruvate, 2-oxoglutarate and the $\mathrm{NAD}^{+}$-dependent isocitrate dehydrogenases) were shown to be allosterically stimulated by $\mathrm{Ca}^{2+}$ ions, and regulated by agonist-induced increases in cytosolic and hence mitochondrial $\mathrm{Ca}^{2+}$ concentration. Activation of these enzymes by $\mathrm{Ca}^{2+}$ can stimulate mitochondrial ATP synthesis at the same time as there is an increased need to supply ATP-requiring processes in the cytosol (secretion, motility, protein synthesis, etc.) (Hansford 1985, Hajnoczky et al. 1995, Denton and McCormack 1998, Robb-Gaspers et al. 1998, Rutter and Rizzuto 2000). It was shown that in vivo and under highly physiological conditions, mitochondria in mammalian skeletal muscle take up $\mathrm{Ca}^{2+}$ during contraction induced by motor nerve stimulation and rapidly release it during relaxation. The mitochondrial $\mathrm{Ca}^{2+}$ increase occurs both during a single twitch and upon tetanic contraction (Rüdiger et al. 2004). These recent findings document a role of $\mathrm{Ca}^{2+}$ in regulation of mitochondrial respiration. The signaling pathways which stimulate changes in cellular $\mathrm{Ca}^{2+}$ may also be important in regulation of the metabolic rate.

The main aim of our present study was to test what cellular regulatory pathways could be included in this stimulatory process. Therefore, we analyzed the tissue levels of second messengers: cyclic 3', 5'adenosine monophosphate (cAMP), cyclic 3', 5'guanosine monophosphate (cGMP), and D-myo-inositol 1, 4, 5-trisphosphate (IP3) and their alterations after changes of the perfusion flow rate in order to test a participation of the three most popular intracellular regulatory pathways in this process. Muscle isolation and in vitro perfusion influenced the level of the second messengers in comparison with in vivo concentrations. Only in IP3 there was a significant change (an expressive decrease) in tissue level after increasing of perfusion flow rate, which indicates, that IP3 signaling pathway may play role in this process of metabolic stimulation. How this signaling process can be involved in the final change in energy metabolism is still uncertain.

\section{Methods}

Male Wistar rats were housed at temperature 20-22 ${ }^{\circ} \mathrm{C}$ with a $12 \mathrm{~h}$ light $-12 \mathrm{~h}$ dark cycle. Food and water were provided ad libitum. All handling of rats was carried out in full compliance with the guidelines on the care and management of animals established by the European Community and the experiments were approved by the Resort Committee of the Ministry of Education of the Czech Republic. After transferring to the laboratory, the rats were anesthetized by an intraperitoneal injection of Thiopental in a dose of $50 \mathrm{mg} / \mathrm{kg}$.

In a control group of rats (control $1, \mathrm{n}=8$ ), the skin on the ventromedial part of the thigh was incised, the muscles were exposed and a substantial part of the musculus gracilis cranialis was freeze-clamped with metal tongs precooled in liquid nitrogen; then the animal was killed in a deep anesthesia. The sample was quickly divided in two parts, weighed, and stored at $-74{ }^{\circ} \mathrm{C}$ until second messenger analysis was performed. One part served for the analysis of cAMP and cGMP, the other for 
analysis of IP3.

In other experimental groups, the gracilis muscle was vascularly isolated after anesthesia. All vessels upstream and downstream of the muscular branches of the gracilis muscle were ligated, except for small branches of the femoral and saphenous artery and vein. The femoral artery was cannulated, the tendons of the muscle were separated from the bones and the muscle was isolated from the surroundings tissue; the animal was killed in a deep anesthesia. The samples of the second control group (control $2, \mathrm{n}=8$ ) were frozen immediately after isolation and treated as control 1 samples. In other experimental groups the muscle was flushed with saline containing heparin and placed in precooled saline in a dish. The cannula was rapidly connected to a perfusion system, and the muscle was perfused with a cell-free medium of high partial oxygen pressure $\left(\mathrm{PO}_{2}\right.$ about 90 $\mathrm{kPa}$ ). The muscle was mounted at its resting length to a stainless steel wire and placed in a small glass metabolic chamber (volume $1.5 \mathrm{ml}$ ) at $28{ }^{\circ} \mathrm{C}$, where it was superfused with a low $\mathrm{PO}_{2}$ medium (about $1 \mathrm{kPa} \mathrm{PO}_{2}$ ) at a flow rate of $2 \mathrm{ml} / \mathrm{min}$. The perfusion medium was a cell-free, Krebs-Henseleit bicarbonate buffer (mM: 118.5 $\mathrm{NaCl}, 4.75 \mathrm{KCl}, 2.5 \mathrm{CaCl}, 1.2 \mathrm{KH}_{2} \mathrm{PO}_{4}, 25 \mathrm{NaHCO}_{3}$, $1.2 \mathrm{MgSO}_{4} ; \mathrm{pH} 7.4$ ), with bovine serum albumin (BSA $5 \%$ ) and glucose (5 $\mathrm{mM})$; the superfusion medium was the same except for the BSA. The perfusion medium was equilibrated with a gas mixture of $95 \% \mathrm{O}_{2}$ and $5 \% \mathrm{CO}_{2}$, whereas superfusion medium was equilibrated with a gas mixture $1 \% \mathrm{O}_{2}, \quad 5 \% \mathrm{CO}_{2}$ and $94 \% \mathrm{~N}_{2}$. Oxygen consumption was measured with a polarographic oxygen sensor (Orbisphere Laboratories, Switzerland) and perfusion pressure with a transducer (Keller, Germany); both were continuously recorded on a line recorder. The details about perfusion method are in the original work (Štefl et al. 1999). After finishing the perfusion experiment, the muscle was quickly removed from the chamber and freeze-clamped in liquid nitrogen cooled tongs. The sample was treated as the samples of control 1 group and stored in $-74{ }^{\circ} \mathrm{C}$ until second messenger analysis was performed.

Three different experimental groups were used for different perfusion flow rates. Group perfusion 1 ( $\mathrm{n}=8$, perfused for $100 \mathrm{~min}$ at the rate of $0.055 \mathrm{ml} / \mathrm{min}$ ), group perfusion $2(\mathrm{n}=8$, perfused for $40 \mathrm{~min}$ with the flow rate $0.055 \mathrm{ml} / \mathrm{min}$ and then for $5 \mathrm{~min}$ with the increased flow rate $0.120 \mathrm{ml} / \mathrm{min}$ ), and group perfusion 3 ( $\mathrm{n}=8$, perfused $40 \mathrm{~min}$ with the flow rate $0.055 \mathrm{ml} / \mathrm{min}$ and then for $60 \mathrm{~min}$ with increased flow rate 0.120 $\mathrm{ml} / \mathrm{min}$ ). This increase of perfusion flow rate in group perfusion 3 was the experimental stimulus that should initiate the increase in metabolic rate and mitochondrial ATP production in skeletal muscle (as described by Janovská et al. 1999, Štefl et al. 1999); the shorter stimulus (perfusion 2 - brief increasing of the flow rate for $5 \mathrm{~min}$ ) was chosen as an alternative model for the detection of second messengers stimulation.

The analysis of intracellular second messengers - cyclic 3', 5'-adenosine phosphate (cAMP), cyclic 3', 5 '-guanosine phosphate (cGMP) and D-myo-inositol 1, 4, 5-trisphosphate (IP3) - was performed by assay systems of Amersham Biosciences: cAMP (Enzyme immunoassay system, kit code RPN 225), cGMP (Enzyme immunoassay system, kit code RPN 226), and IP3 $\left({ }^{3} \mathrm{H}\right]$ Biotrack assay system, kit code TRK 1000). The muscle samples stored in deep-freeze box were pulverized in a mortar under liquid nitrogen and then the samples were homogenized in appropriate cooled acid and treated according to relevant method.

The first part of the muscle (cAMP and cGMP samples) was homogenized in $6 \%$ trichloroacetic acid (to give $10 \% \mathrm{w} / \mathrm{v}$ homogenate) at $4{ }^{\circ} \mathrm{C}$ and centrifuged at $2000 \mathrm{x} \mathrm{g}$ for $15 \mathrm{~min}$ at $4{ }^{\circ} \mathrm{C}$. The supernatant was quantitatively divided to two plastic test tubes (the first for cAMP, the second for cGMP). The supernatant was washed 4 times with 5 volumes of water saturated diethyl ether; the upper ether layer was discarded after each wash. The remaining aqueous extracts were lyophilized and dried extracts were dissolved in assay buffer of an appropriate kit prior to analysis. The microplate assays are based on competition between unlabeled cAMP (or cGMP) and a fixed quantity of peroxidase-labeled cAMP (or cGMP), for a limited number of binding sites on a cAMP (or cGMP) specific antibody. The optical density of analytic samples together with blanks, standards and non-specific binding wells was measured using microplate reader at $450 \mathrm{~nm}$ and the results were evaluated on the basis of percentage binding $\left(\mathrm{B} / \mathrm{B}_{0}\right)$ from the calibration curves.

IP3 samples (the second part of the muscle) were homogenized in ice-cold $4.2 \%$ perchloric acid (to give $5 \% \mathrm{w} / \mathrm{v}$ homogenate) and incubated on ice for $20 \mathrm{~min}$. The sample was centrifuged at $2000 \mathrm{x}$ g for $15 \mathrm{~min}$ at $4{ }^{\circ} \mathrm{C}$ and the supernatant was quantitatively decanted to the plastic centrifuge tube. The supernatant was neutralized to $\mathrm{pH} 7.5$ with ice-cold $1.8 \mathrm{M} \mathrm{KOH}$ containing $60 \mathrm{mM}$ HEPES buffer. $\mathrm{KClO}_{4}$ was sedimented by centrifugation at $2000 \times \mathrm{g}$ for $15 \mathrm{~min}$ at $4{ }^{\circ} \mathrm{C}$ and 
supernatant aliquot was quantitatively transferred to plastic test tube. The analysis by the Biotrack assay system is based on competition between $\left[{ }^{3} \mathrm{H}\right.$-labeled (the tracer) and unlabeled IP3 in standards or samples for binding to a binding protein prepared from bovine adrenal cortex. The bound IP3 is then separated from the free IP3 by centrifugation, which brings the binding protein to the bottom of the tube. The free IP3 in the supernatant was discarded by a simple decantation, leaving the bound fraction adhering to tube. After resuspension in water the pellet was immediately decanted into scintillation vials and $10 \mathrm{ml}$ of the scintillation fluid were added to each vial. The radioactivity (cpm) was measured on a $\beta$-scintillation counter and data were evaluated on the basis of percentage binding $\left(\mathrm{B} / \mathrm{B}_{0}\right)$ from the calibration curve. The possible range of the standard curve of this kit was 0.19 $25 \mathrm{pmol}$ IP3/tube (the final equivalent of the muscular tissue corresponding to the tube sample after all previous processing was maximally $4.9 \mathrm{mg}$ w.w., i.e. the lower limit for tissue analysis of IP3 was about $40 \mathrm{pmol} / \mathrm{g}$ w.w.).

Protein content of the tissue samples was measured after dissolving the sediments after centrifugation of homogenates in $1 \mathrm{~N} \mathrm{NaOH}$ and analyzed according to Lowry et al. (1951).

Results are expressed as means \pm S.E.M. The statistical evaluation was performed by an analysis of variance (one way ANOVA) or by non-parametric Kruskal-Wallis test (when a normal distribution of data was not confirmed); a post-hock tests (Student t-test or Mann-Whitney unparametric test) were further used for comparison of differences between two means at a significance level $\mathrm{P}<0.05$.

\section{Results}

Experiments with different perfusion flow rates showed marked increase of oxygen consumption of isolated skeletal muscle during higher flow rate (Fig. 1). The increase of $\mathrm{O}_{2}$ consumption above the basal level was significant after short- as well as after long-lasting increasing the flow rate: $125 \mathrm{nmol} \mathrm{O}_{2} \min ^{-1} \mathrm{~g}^{-1}$ at perfusion 2 group and $101 \mathrm{nmol} \mathrm{O}_{2} \min ^{-1} \mathrm{~g}^{-1}$ at perfusion 3 group $(\mathrm{P}<0.01)$. Oxygen consumption during constant low perfusion flow rate lasting $100 \mathrm{~min}$ (perfusion 1 group) demonstrates a stable metabolic rate $(96 \pm 12$ nmol $\mathrm{O}_{2} \min ^{-1} \mathrm{~g}^{-1}$ ), with lower oxygen consumption in comparison with other two groups, although the delivery of oxygen was sufficiently high $(256 \pm 5$ nmol $\left.\mathrm{O}_{2} \min ^{-1} \mathrm{~g}^{-1}\right)$. This fact documents a stimulation of metabolic rate after increasing the perfusion flow rate in the tested skeletal muscle model in agreement with our previous studies.

Perfusion pressure (oscillating as systolic/ diastolic due to the peristaltic pump) decreased to a lower stable level after placement of the muscle into the metabolic chamber. Increasing the perfusion flow rate induced a rise of perfusion pressure, which continued during the total perfusion time (Fig. 2). This indicates that the increase of transluminal pressure in vascular net of muscle can play a role in the stimulation of some signaling pathways at least in muscular vessels.

The analysis of the tissue concentrations of second messengers (cAMP, cGMP, and IP3) revealed significant differences among the experimental groups. Due to a rather large dissipation of cAMP content under low perfusion flow rate (perfusion 1 group) we were not successful to detect a significant difference between this group and groups perfusion 2 and perfusion $3(\mathrm{P}>0.30)$ (Fig. 3). Similarly, the differences in cGMP levels (Fig. 3) among groups perfusion 1, 2, and 3 were not significant. These results indicate that the change in perfusion flow rate has no direct relation to signaling pathways using cAMP and cGMP second messengers in skeletal muscle fibers.

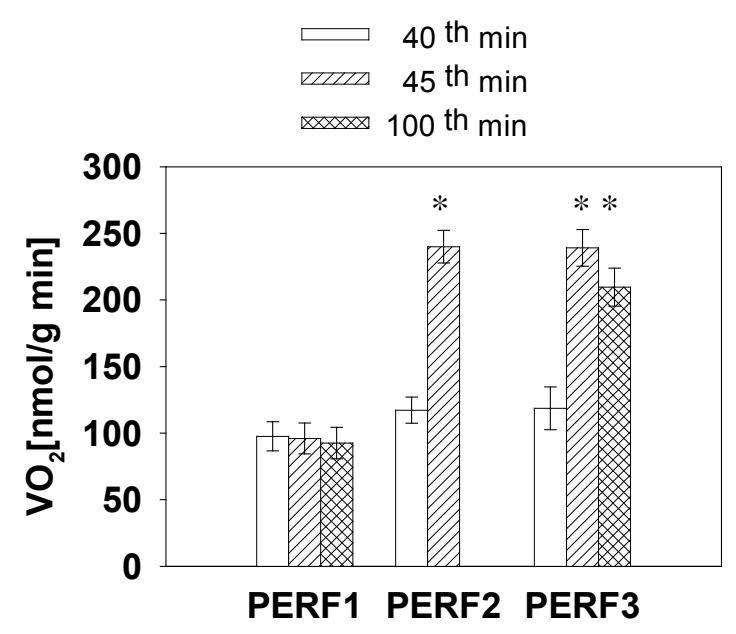

Fig. 1. Oxygen consumption of isolated perfused skeletal muscles. PERF1 - perfusion 1 group (low perfusion flow rate $0.055 \mathrm{ml} / \mathrm{min}$ for $100 \mathrm{~min}$ ); PERF2 - perfusion 2 group (low perfusion flow rate $0.055 \mathrm{ml} / \mathrm{min}$ for $40 \mathrm{~min}$ and increase to high flow rate $0.120 \mathrm{ml} / \mathrm{min}$ for $5 \mathrm{~min}$ ); PERF3 - perfusion 3 group (low perfusion flow rate $0.055 \mathrm{ml} / \mathrm{min}$ for $40 \mathrm{~min}$ and increase to high flow rate $0.120 \mathrm{ml} / \mathrm{min}$ for $60 \mathrm{~min}$ ). * - significant difference in comparison with values measured under low perfusion flow rate $(\mathrm{P}<0.01)$. 
The exact analysis of IP3 level was possible only in groups control 1, control 2, and perfusion 1. The concentration of IP3 in muscle samples from groups perfusion 2 and perfusion 3 decreased below the minimal value of the calibration curve of the appropriate analytic kit (40 pmol IP3/g w.w. of muscle tissue). We arbitrary accepted this low level of IP3 as zero in comparison with other samples. Slow isolation of the muscle accompanied by transient hypoxia (control 2) also induced a large decrease of IP3 level in muscle compared to concentration in vivo (control 1); low perfusion flow rate

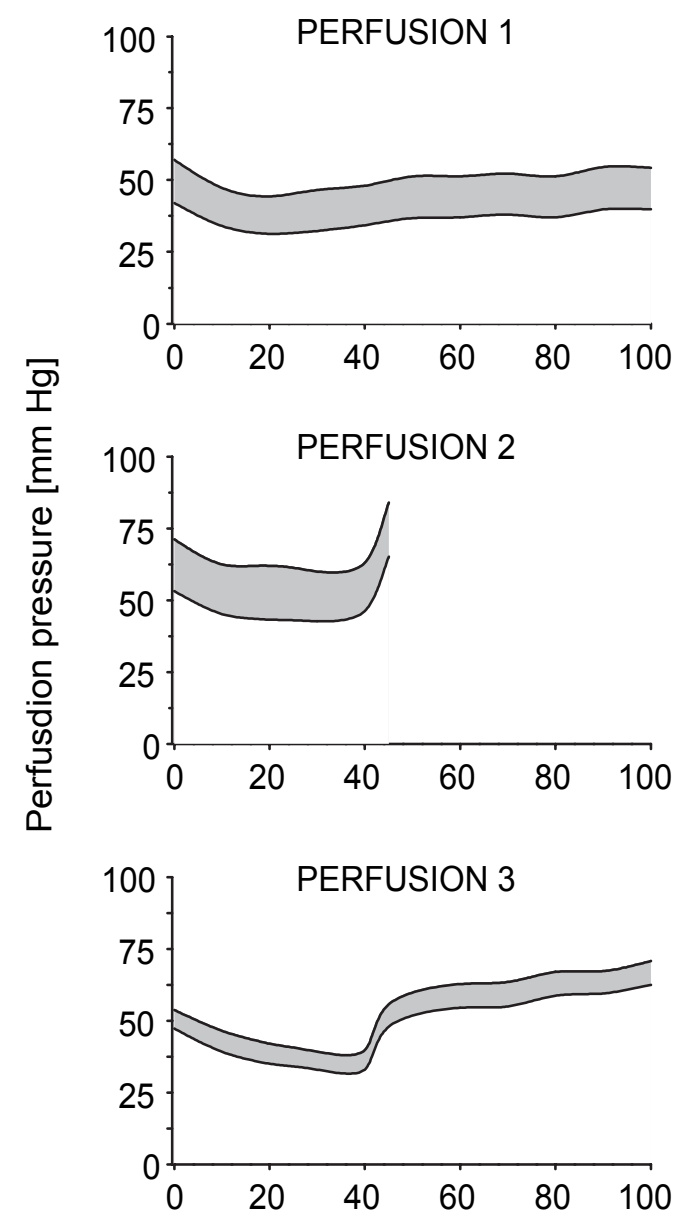

Fig. 2. Perfusion pressure changes after increasing the flow rate. PERFUSION 1 group (low perfusion flow rate $0.055 \mathrm{ml} / \mathrm{min}$ for $100 \mathrm{~min}$ ); PERFUSION 2 group (low perfusion flow rate 0.055 $\mathrm{ml} / \mathrm{min}$ for $40 \mathrm{~min}$ and increase to high flow rate $0.120 \mathrm{ml} / \mathrm{min}$ for $5 \mathrm{~min}$ ); PERFUSION 3 group (low perfusion flow rate 0.055 $\mathrm{ml} / \mathrm{min}$ for $40 \mathrm{~min}$ and increase to high flow rate $0.120 \mathrm{ml} / \mathrm{min}$ for $60 \mathrm{~min}$ ). with medium containing high oxygen level induced again a rise of IP3 level (difference between control 1 and perfusion 1 is not significant, $\mathrm{P}>0.70$ ). Increasing the perfusion flow rate then lead to a marked fall of IP3 level in muscle tissue (in comparison with perfusion 1 group, $\mathrm{P}<0.05$ ) (Fig. 3).

The analysis of sample proteins and concentrations of second messengers in units per $\mathrm{mg}$ of protein gave similar results when comparing the significance of differences among the experimental groups (Table 1).

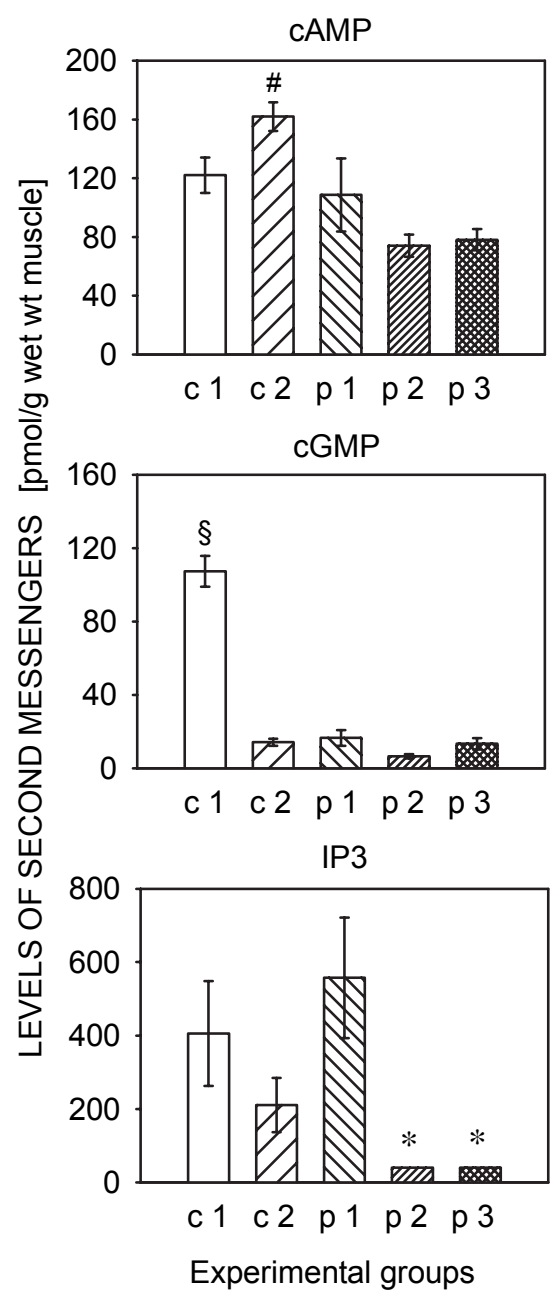

Fig. 3. Tissue levels of cAMP, cGMP, and IP3 (means \pm SEM; $n=$ 8). c 1 - control 1 group (muscles frozen in vivo); c 2 - control 2 group (slowly isolated non-perfused muscles - arbitrary anoxia); $p$ 1 - perfusion 1 group (low perfusion flow rate $0.055 \mathrm{ml} / \mathrm{min}$ for $100 \mathrm{~min}$ ); $\mathrm{p} 2$ - perfusion 2 group (low perfusion flow rate 0.055 $\mathrm{ml} / \mathrm{min}$ for $40 \mathrm{~min}$ and increase to high flow rate $0.120 \mathrm{ml} / \mathrm{min}$ for $5 \mathrm{~min}$ ); p 3 - perfusion 3 group (low perfusion flow rate 0.055 $\mathrm{ml} / \mathrm{min}$ for $40 \mathrm{~min}$ and increase to high flow rate $0.120 \mathrm{ml} / \mathrm{min}$ for $60 \mathrm{~min})$. Significant differences: \# compared to control 1 $(\mathrm{P}<0.05)$, § compared to other groups $(\mathrm{P}<0.01)$, * compared to groups control 1 , control 2 , and perfusion $1(\mathrm{P}<0.05)$ 
Table 1. Tissue levels of second messengers in perfused/superfused rat skeletal muscles (musculus gracilis cranialis) in comparison with in vivo concentrations.

\begin{tabular}{lcccc}
\hline & Control 1 & Perfusion 1 & Perfusion 2 & Perfusion 3 \\
\hline cAMP [fmol/mg protein] & & & & \\
Mean & 779 & 1220 & 598 & 899 \\
SEM & 81 & 268 & 65 & 74 \\
$n$ & 8 & 8 & 8 & 8 \\
cGMP [fmol/mg protein] & & $*$ & 51 & $*$ \\
Mean & 661 & 194 & 8 & 34 \\
SEM & 38 & 52 & 8 & 8 \\
$n$ & 7 & 8 & $*$ & $*$ \\
IP3 [fmol/mg protein] & & & $<475$ & $<475$ \\
Mean & 3990 & 6160 & 0 & 0 \\
SEM & 1210 & 1780 & 8 & 8 \\
$n$ & 5 & 7 & & 8 \\
\hline
\end{tabular}

CAMP - cyclic adenosine 3',5' -monophosphate; cGMP - cyclic guanosine 3',5'-monophosphate; IP3 - inositol 1,4,5-trisphosphate, control 1 - samples in vivo; perfusion 1 - samples from muscles perfused with low perfusion flow rate $(0.055 \mathrm{ml} / \mathrm{min})$ for $100 \mathrm{~min}$; perfusion 2 - samples from muscles perfused 40 min with low perfusion flow rate $(0.055 \mathrm{ml} / \mathrm{min})$ and then with increased flow rate $(0.120 \mathrm{ml} / \mathrm{min})$ for $5 \mathrm{~min}$; perfusion 3 - samples from muscles perfused $40 \mathrm{~min}$ with low perfusion flow rate $(0.055 \mathrm{ml} / \mathrm{min})$ and then with increased flow rate $(0.120 \mathrm{ml} / \mathrm{min})$ for $60 \mathrm{~min}$, * - significant difference from control $1(\mathrm{P}<0.05)$.

\section{Discussion}

The study about involvement of intracellular signaling pathways in the changes of skeletal muscle metabolism induced by increasing the perfusion flow rate is based upon the assumption that the mechanical stimulus is somehow converted into an intracellular chemical signal. What is probably a primary and dominant effect is a reaction of endothelial and smooth muscle cells of vascular net to mechanical stimulus. The vascular myogenic response refers to the acute reaction of a blood vessel to a change in transmural pressure (Davis and Hill 1999). Blood vessels respond to transmural pressure elevation with constriction and to pressure reduction with dilation. However, the response of isolated organs to pulsatile perfusion may involve more than simply a pressure effect, possibly due to release of endothelium-derived vasoactive factors (Folkow 1952, Hutcheson and Griffith 1991). There is evidence that mechanical stimulus may affect intracellular signaling pathways, e.g. G proteins may be activated after mechanic stimulation in smooth muscles (Wiersbitzky et al. 1994) as well as in skeletal muscles (Vandenburgh et al. 1995).

Besides direct mechanical influence there is a possibility that partial oxygen pressure $\left(\mathrm{PO}_{2}\right)$ changes can influence the reactivity of muscular vessels (Frisbee et al. 2002). This effect is apparently important for adjustment of vascular reactivity in the reaction to ischemia during preparation of our muscular model.

Mechanical or hypoxic stimulation of muscular vessels leads to production of some substances - NO, endothelial factors, $\mathrm{PGI}_{2}$, prostacycline, and others (Kerkhof et al. 1999, Frisbee et al. 2002). Their eventual extracellular release can influence receptors in the membrane of skeletal muscle fibers and thus initiate a signaling pathway that may induce a change in regulation of metabolic rate; a direct intracellular effect is also possible after entering the skeletal muscle cell (e.g. in the case of NO).

A lot of experimental findings show that the role of nitric oxide in regulation of metabolism in skeletal muscle is important. The action of NO in skeletal muscle is exemplified in its binding to cytochrome-c oxidase, which reversibly inhibits the enzyme and thus cell respiration (Borutaite and Brown 1996), and to guanylate cyclase, which activates the enzyme and thereby raises cGMP levels (Murad 1996).

In our skeletal muscle model, the low level of perfusion pressure during low flow rate (Fig. 2) indicated that the production of $\mathrm{NO}$ and its effects on relaxation of vascular smooth muscles might be important. This 
supports the opinion that higher input or synthesis of NO in skeletal muscle fibers can inhibit oxidative phosphorylation and stimulate glycolysis (Balon and Nadler 1994, Reid 1998). This is in good agreement with our findings on the ratio between glycolytic/oxidative phosphorylation pathways of ATP synthesis during low perfusion flow rate (Janovská et al. 1999). Increasing the perfusion flow rate that in our experiments induces the accrual of perfusion pressure could reduce the input of NO to muscle fibers (or decrease the synthesis of NO directly in muscle cells) and thus abolish its inhibiting effect on mitochondrial functions, i.e. elevate oxidative metabolism. The rise of oxygen consumption as a consequence of increasing the perfusion flow rate is clearly documented in our results (see Fig. 1). Unfortunately, the experimental design did not allow the direct measurement of NO in our model of skeletal muscle perfused and superfused in vitro.

Because the another known effect of NO is its stimulatory influence on the cytosolic guanosine-cyclase activity leading to the activation of signaling pathway associated with the production of cGMP, we measured the tissue level of cGMP. cGMP can directly gate certain ion channels and regulates the activity of specific classes of phosphodiesterases (Schmidt et al. 1993). Many actions of cGMP are mediated by cGMP-dependent kinase. However, the downstream targets of cGMPdependent kinase are, with rare exception, not known (Stamler and Meissner 2001). Our analysis of tissue concentrations of cGMP in three different perfusion groups did not prove any significant change in cGMP level in response to changes of perfusion flow rate. This indicates that a signaling pathway using cGMP does not importantly participate in the regulation of skeletal muscle metabolism under our experimental conditions. The potential activity of NO based on the measurement of cGMP indicates that it is small both during low as well as during high perfusion rates. This indirect assessment does not support the possible contribution of $\mathrm{NO}$ to changes of metabolic regulation induced by the increasing flow rate. However, it is important to perceive that this is only indirect survey and that an improvement of methodical background could help in replenishment of the problems in the future.

The spectrum of effects induced by cAMP is very wide. For the possible regulatory influence on the metabolic rate of skeletal muscle, a cAMP-dependent protein kinase (PKA) localized in mammalian mitochondria with the catalytic side at the matrix side of the membrane may be important. It phosphorylates number of proteins. One of these is this $18 \mathrm{kDa}$ (ironprotein fraction) subunit of the mammalian complex I (NADH-ubiquinone oxidoreductase) of the respiratory chain (Papa et al. 2002). cAMP-dependent phosphorylation of the $18 \mathrm{kDa}$ protein is associated with stimulation of complex I and overall respiratory activity. Mitochondria have a $\mathrm{Ca}^{2+}$-inhibited phosphatase, which dephosphorylates $18 \mathrm{kDa}$ phosphoprotein of complex I. The increased level of cAMP could thus play a role in stimulation of the respiratory chain and higher level of $\mathrm{Ca}^{2+}$ in the mitochondrial matrix that could be induced by IP3 could also stimulate the respiration.

In perfused rat heart tissue cAMP increased with each ischemic event and normalized upon reperfusion, while phosphodiesterase activity showed an opposite reaction - a reduction during ischemia and an increase during reperfusion (Lochner et al. 1998). The higher level of cAMP in our experiments after slow isolation of skeletal muscle (control 2 group), i.e. under ischemic conditions, is in agreement with this phenomenon as is evident from the decrease of cAMP during perfusion. Possible changes in the activity of PDE may therefore play a relevant role in these effects. If this regulatory pathway plays a role in the stimulation of oxygen consumption due to higher perfusion flow rate, we would expect the elevation of cAMP level after increasing the flow rate. However, in comparison with tissue concentration in vivo there is no significant change in cAMP after increasing the perfusion flow rate and this does not support possible role of this signaling pathway in the regulation of a metabolic rate in our model.

The evaluation of increasing perfusion flow rate on cellular level of IP3 and its possible effect on metabolic regulation is difficult. Our results showed an enormous decrease in IP3 concentration following higher perfusion rate that lasted over a long time period. It is known that increasing of IP3 stimulates $\mathrm{Ca}^{2+}$ sparks or waves in the cytosol and that $\mathrm{Ca}^{2+}$ have a number of regulatory cellular functions. In accordance with this knowledge we would expect stimulation of IP3 production as a preconditioning of regulatory increase of oxygen consumption after increasing the perfusion flow rate. Nevertheless, we have found an opposite reaction, because the level of IP3 significantly fell down. This rather indicates a lower cellular level of calcium ions under these perfusion conditions.

The theory of metabolic feedback regulation is an 
regulation which does not exclude the role of $\mathrm{Ca}^{2+}$ but does not assume it is the most important phenomenon. The effective regulations of the respiration are explained by the mechanisms of functional coupling within supramolecular complexes in mitochondria, and at the subcellular level within the intracellular energetic units (for review see Saks et al. 2004). The model of mitochondrial regulation of skeletal muscles is based upon knowledge about metabolic and physical structure of systems producing and using energy (Kemp et al. 1998). It assumes that cytosolic creatine kinase reaction is not in equilibrium and that important change in creatine kinase activity plays a substantial role in regulatory process of energy metabolism.

Recently, great interest is paid to an important regulatory protein - the enzyme 5'-AMP-activated protein kinase (AMPK). This enzyme has emerged as a key regulator of carbohydrate and fat metabolism, working as a fuel 'sensor' in most tissues. In skeletal muscle, AMPK is activated in response to various metabolic stresses such as hypoxia, hyperosmolarity, and exercise (Winder and Hardie 1996, 1999, Hayashi et al. 1998, 2000).

It is therefore possible that ischemia induced by slow isolation in our muscle model leads to stimulation of AMPK in consequence of the rise of 5'AMP level (and an increase of the AMP/ATP ratio). In accordance with prevailing glycolytic ATP production due to low perfusion flow rate (Janovská et al. 1999, Štefl et al. 1999) we can suppose that its activity still remains high. Increasing the perfusion flow rate that stimulates oxygen consumption of the muscle and mitochondrial synthesis of ATP, probably decreases the activity of AMPK and in consequence stimulates the activity of creatine kinase, because it was proved that these two energy-regulating systems are linked in skeletal muscle (Ponticos et al. 1998, Neumann et al. 2003). It may be the significant effect in the regulation of metabolic rate of our perfusedsuperfused skeletal muscle model in vitro. What signaling frameworks, induced by increasing the flow rate, play a role in the possible modulating activity of these regulatory enzymes is unfortunately not yet clear. The measurements of selected second messengers tissue levels (cAMP, cGMP, and IP3) show that only signaling pathway including IP3 is markedly influenced (significantly reduced) by the change in perfusion flow rate. The explanation whether this effect may be important for possible affecting of AMPK or creatine kinase activity is impossible on the basis of available information. Nevertheless, this supports our future research interest in the problem of skeletal muscle regulation of energy metabolism.

\section{Acknowledgements}

The authors thank Dr. Jarmila Šavlíková for technical support and Prof. J. Mejsnar for help with preparation of muscle samples. This work was supported by Grant GAČR No. 305/02/1565 and VZ MSM 113100003. Preliminary results (Štefl et al. 2005) were presented at the $81^{\text {st }}$ Meeting of the Czech and Slovak Physiological Societies in Košice, February 2-4, 2005.

\section{References}

BALON TW, NADLER JL: Nitric oxide release is present from incubated skeletal muscle preparations. $J$ Appl Physiol 77: 2519-2521, 1994.

BORUTAITE V, BROWN GC: Rapid reduction of nitric oxide by mitochondria, and reversible inhibition of mitochondrial respiration by nitric oxide. Biochem J 315: 295-299, 1996.

CHINET AE, MEJSNAR J: Is resting muscle oxygen uptake controlled by oxygen availability to cells? $J$ Appl Physiol 66: 253-260, 1989.

CLARK MG, COLQUHOUN EQ, RATTIGAN S, DORA KA, ELDERSHAW TPD, HALL JL, YE J: Vascular and endocrine control of muscle metabolism. Am J Physiol 268: E797-E812, 1995.

DAVIS MJ, HILL MA: Signaling mechanisms underlying the vascular myogenic response. Physiol Rev 79: 387-423, 1999.

DENTON RM, MCCORMACK JG: On the role of the calcium transport cycle in the heart and other mammalian mitochondria. FEBS Lett 119: 1-8, 1998.

FOLKOW BA: A study of the factors influencing a tone of denervated blood vessels performed at various pressures. Acta Physiol Scand 27: 99-117, 1952. 
FRISBEE JC, MAIER KG, FALCK JR, ROMAN RJ, LOMBARD JH: Integration of hypoxic dilation signaling pathways for skeletal muscle resistance arteries. Am J Physiol 283: R309-R319, 2002.

HAJNOCZKY G, ROBB-GASPERS LD, SEITZ MB, THOMAS AP: Decoding of cytosolic calcium oscillations in the mitochondria. Cell 82: 415-424, 1995.

HANSFORD RG: Relation between mitochondrial calcium transport and control of energy metabolism. Rev Physiol Biochem Pharmacol 102: 1-72, 1985.

HAYASHI T, HIRSHMAN MF, KURTH EJ, WINDER WW, GOODYEAR LJ: Evidence for 5'AMP-activated protein kinase mediation of the effect of muscle contraction on glucose transport. Diabetes 47: 1369-1373, 1998.

HAYASHI T, HIRSHMAN MF, FUJII N, WITTERS LA, GOODYEAR LJ: Metabolic stress and altered glucose transport: activation of AMP-activated protein kinase as a unifying coupling mechanism. Diabetes 49: 527$531,2000$.

HUTCHESON IR, GRIFFITH TM: Release of endothelium-derived relaxing factor is modulated both by frequency and amplitude of pulsatile flow. Am J Physiol 261: H257-H262, 1991.

JANOVSKÁ A, MEJSNAR JA, ŠTEFL B: Muscle ATP synthesis and utilization, balanced during flow-induced increase of respiration. Mol Cell Biochem 197: 49-52, 1999.

KEMP GJ, MANNERS DN, CLARK JF, BASTIN ME, RADDA GK: Theoretical modelling of some spatial and temporal aspects of the mitochondrion/creatine kinase/myofibril system in muscle. Mol Cell Biochem 184: 249-289, 1998.

KERKHOF CJM, BAKKER ENTP, SIPKEMA P: Role of cytochrome P-450 4A in oxygen sensing and NO production in rat cremaster resistance arteries. Am J Physiol 277: H1546-H1552, 1999.

LOCHNER A, GENADE S, TROMP E, OPIE L, MOOLMAN J, THOMAS S AND PODZUWEIT T: Role of cyclic nucleotide phosphodiesterases in ischemic preconditioning. Mol Cell Biochem 186: 169-175, 1998.

LOWRY OH, ROSEBOROUGH NJ, FARR AL, RANDALL RJ: Protein measurement with the Folin reagent. $J$ Biol Chem 193: 265-275, 1951.

MEJSNAR JA, KUSHMERICK MJ, WILLIAMS DL: Phosphocreatine and ATP concentrations increase during flowstimulated metabolism in a non-contracting muscle. Experientia 48: 1125-1127, 1992.

MURAD F: Signal transduction using nitric oxide and cyclic guanosine monophosphate. JAMA 276: 1189-1192, 1996.

NEUMANN D, SCHLATTNER U, WALLIMANN T: A molecular approach to the concerted action of kinases involved in energy homeostasis. Biochem Soc Transactions 31: 169-174, 2003.

PAPA S, SCACCO S, SARDANELLI AM, PETRUZZELLA V, VERGARI R, SIGNORILE A, TECHNIKOVADOBROVA Z: Complex I and the cAMP cascade in human physiopathology. Biosci Rep 22: 3-16, 2002.

PONTICOS M, QUI LONG LU, MORGAN JE, HARDIE G, PATRIDGE TA, CARLING D: Dual regulation of the AMP-activated protein kinase provides a novel mechanism for the control of creatine kinase in skeletal muscle. EMBO J 17: 1688-1699, 1998.

REID MB Role of nitric oxide in skeletal muscle: synthesis, distribution and functional importance. Acta Physiol Scand 162: 401-409, 1998.

ROBB-GASPERS LD, BURNETT P, RUTTER GA, DENTON RM, RIZZUTO R, THOMAS AP: Integrating cytosolic calcium signals into mitochondrial metabolic responses. EMBO J 17: 4987-5000, 1998.

RÜDIGER R, MONGILLO M, MAGALHAES PJ, POZZAN T: In vivo monitoring of $\mathrm{Ca}^{2+}$ uptake into mitochondria of mouse skeletal muscle during contraction. J Cell Biol 166: 527-536, 2004.

RUTTER GA, RIZZUTO R: Regulation of mitochondrial metabolism by ER $\mathrm{Ca}^{2+}$ release: an intimate connection. Trends Biochem Sci 25: 215-221, 2000.

SAKS VA, KUZNETSOV AV, VENDELIN M, GUERRERO K, KAY L, SEPPET EK: Functional coupling as a basic mechanism of feedback regulation of cardiac energy metabolism. Mol Cell Biochem 256/257: 185-199, 2004.

SCHMIDT HH, LOHMANN SM, WALTER U: The nitric oxide and cGMP signal transduction system: regulation and mechanism of action. Biochim Biophys Acta 1178: 153-175, 1993.

STAMLER JS, MEISSNER G: Physiology of nitric oxide in skeletal muscle. Physiol Rev 81: 209-237, 2001.

ŠTEFL B, MEJSNAR JA, KARASOVÁ J: Levels of energy-related metabolites in intact and isolated perfusedsuperfused rat skeletal muscles. Physiol Res 43: 175-180, 1994. 
ŠTEFL B, MEJSNAR JA, JANOVSKÁ A: Energy metabolism of rat skeletal muscle controlled by the rate of perfusion flow. Exp Physiol 84: 651-663, 1999.

ŠTEFL B, ŽURMANOVÁ J, ŠAVLÍKOVÁ J, MEJSNAR J: Second messengers (cAMP, cGMP and IP3) ion rat skeletal muscle as influenced by the perfusion flow rate. Physiol Res 54: 45P, 2005.

VANDENBURGH HH, SHANSKY J, SOLERSSI R, CROMIAK J: Mechanical stimulation of skeletal muscle increases prostaglandin $\mathrm{F}_{2 \alpha}$ production, cyclooxygenase activity, and cell growth by a pertussis toxin sensitive mechanism. J Cell Physiol 163: 285-294, 1995.

WIERSBITZKY M, MILLS I, SUMPIO BE, GERWITZ H: Chronic cyclic strain reduces adenylate cyclase activity and stimulatory G protein subunit levels in coronary smooth muscle cells. Exp Cell Res 210: 52-55, 1994.

WINDER WW, HARDIE DG: Inactivation of acetyl-CoA carboxylase and activation of AMP-activated protein kinase in muscle during exercise. Am J Physiol 270: E299-E304, 1996.

WINDER WW, HARDIE DG: AMP-activated protein kinase, a metabolic master switch: possible roles in type 2 diabetes. Am J Physiol 277: E1-E10, 1999.

\section{Reprint requests}

Bohumír Štefl, Department of Physiology and Developmental Biology, Viničná 7, 12844 Prague 2, Czech Republic.

E-mail: stefl@natur.cuni.cz 